\title{
Pengaruh SDM Dan Partisipasi Anggota Terhadap Kepuasan Kinerja Koperasi MMS Di Rancaekek
}

\author{
oleh
}

\author{
Dina Fuji A, Risma Andriani, Cindy Sophianti \\ Institut Koperasi Manajemen Indonesia (IKOPIN), Sumedang, Indonesia \\ Email :
}

nasutiondinaaa@gmail.com, rismaandriani096@gmail.com, cindysophianti23@gmail.com

\begin{abstract}
Abstrak
Tujuan penelitian adalah untuk mengetahui pengaruh SDM dan partisipasi terhadap kepuasan kinerja pengurus dikoperasi MMS warung sampah dirancaekek bandung jawa barat, data yang diambil adalah hasil wawancara dan survey langsung ke koperasi MMS warung sampah dirancaekek metode penelitian ini adalah metode kuantitatif pendekatan survey populasi data yang diambil adalah 10 orang anggota nasabah dan wakil ketua koperasi MMS warung sampah rancaekek bandung dengan menentukan hasil kepuasan kinerja pengurus terhadap anggota hasil penelitian menyatakan bahwa pengaruh hasil kepuasan kinerja pengurus positif terhadap kinerja pengurus.
\end{abstract}

Kata kunci : kepuasan anggota, anggota koperasi, Partisipasi anggota, SDM, kinerja koperasi.

\begin{abstract}
The purpose of the study was to determine the effect of human resources and participation on the performance satisfaction of the management of the MMS cooperative, the garbage stalls in Bandung, West Java, the data taken were the results of interviews and direct surveys to the MMS cooperative, the garbage stalls in the dirancaekek. This research method is a quantitative method with a population survey approach. 10 customer members and deputy chairman of the MMS cooperative, the rancaekek garbage shop, Bandung, by determining the results of the satisfaction of the management's performance on the members.
\end{abstract}

Keywords : member satisfaction, cooperative members, member participation, human resources, cooperative performance.

\section{Pendahuluan}

Koperasi adalah badan usaha atau badan hukum yang anggotanya saling bekerja sama dalam kegiatan ekonomi. Menurut Bapak Koperasi Indonesia Mohammad Hatta, koperasi adalah usaha bersama untuk memperbaiki nasib penghidupan ekonomi berdasarkan semangat tolong menolong "seorang untuk semua dan semua untuk seorang" Perkembangan koperasi saat ini didukung oleh perkembangan usaha kecil dan menengah (UKM) dibandung khususnya dikecamatan rancaekek yang semakin pesat. Seiring dengan meningkatnya perekonomian masyarakat dirancaekek, koperasi diharapkan dapat 
membantu di dalam penyediaan dana untuk membiayai dan mengembangkan usaha industri, pertanian, perdagangan maupun sektor non keuangan lainnya. Sesuai dengan Peraturan Menteri Negara Koperasi dan Usaha Kecil dan Menengah Republik Indonesia.

No.20/Per/M.KUKM/XI/2008. Salah satu lembaga ekonomi yang berperan dalam membangun perekonomian diIndonesia adalah koperasi MMS warung sampah yang berada dikampung pagaden RT 01/RW 05 desa linggar kecamatan rancaekek kabupaten bandung, koperasi ini berdiri sejak 3 tahun yang dengan jenis koperasi produksi dengan unit usaha didalamnya seperti simpan pinjam, olah sampah menjadi barang berguna, pertanian dan masih banyak, sampah olahan dari masyarakat basic dari koperasi ini adalah sadar lingkungan. Tempat sosialisasi satu desa dengan beranggotakan berjumlah 100 orang sudah termasuk internal 50 orang. tercatat sampai tahun 2020 total jumlah koperasi diKota bandung cukup tinggi yaitu sekitar 7.000 koperasi. Namun, dari jumlah tersebut, hanya sekitar 700 koperasi yang aktif, menunjukkan bahwa koperasi yang berpredikat sehat kisaran 700 unit, dan yang tidak sehat kisaran 6.300 koperasi termasuk berkedok koperasi yang ternyata lintah darat.

\section{Kajian Teoritis}

Berdasarkan hasil wawancara yang kami lakukan terhadap wakil ketua koperasi MMS warung sampah bapak ajun dalam mensosialisasikan koperasi ini ada beberapa tantangan dan proses untuk mengenalkan koperasi ini dengan kultur dan sosialisasi dengan merubah pola perilaku masyarakat sekitar dengan cara bagaimana butuh kearifan lokal yang harus dijaga, sadar atas lingkungan da peka terhadap sekitarnya. permasalahan internal atau pengaruh besar terhadap koperasi ini adalah SDM yang kurang ter sosialisasika kepada masyarakat, kurangnya pelayanan yang maksimal terhadap anggota. Disini ada stuktur organisasi pengurus koperasi MMS warung sampah sebagai berikut

\section{STRUKTUR ORGANISASI PENGURUS KOPERASI MMS WARUNG SAMPAH}

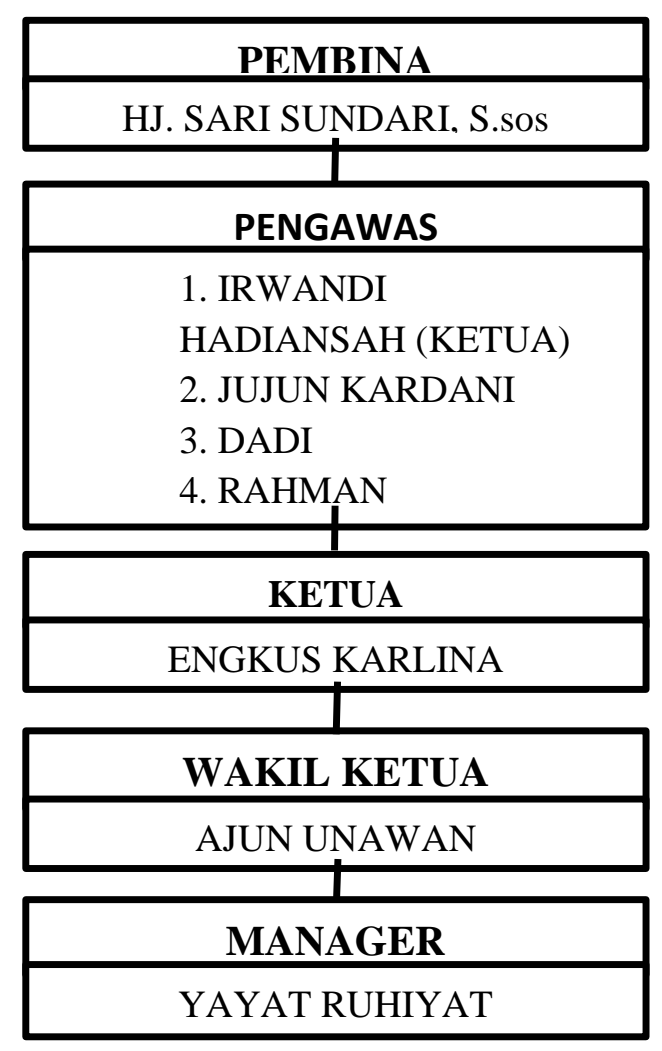




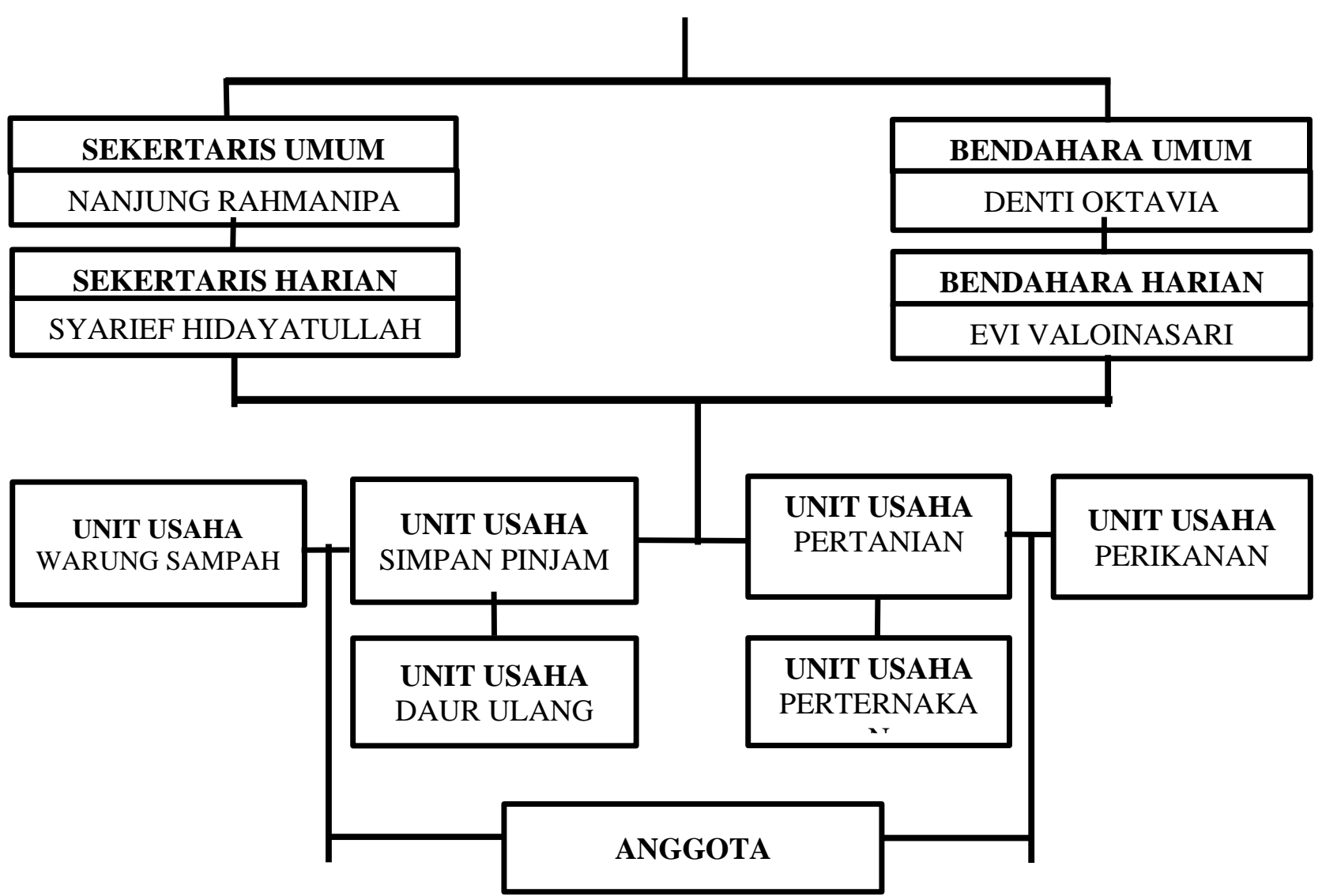

Dari struktur diatas bahwa yang akan kita analisis adalah pengurus terhadap SDM/anggota dengan kinerja dan partisipasinya terpenuhi atau tidaknya, dengan adanya koperasi ini juga pemanfaatan lingkungan sangat baik terhadap wilayah atau kebersihan lingkungan sekitar rancaekek diketahui juga bahwa daerah tersebut sering terkena banjir karena penumpukan sampah maka nya adanya koperasi ini akan sangat membantu masyarakat sekitar.

Sumber Daya Manusia (SDM) adalah orang-orang yang merancang dan menghasilkan barang dan jasa, mengalokasikan sumber daya finansial, mengawasi mutu, serta merumuskan seluruh strategi untuk mencapai sasaran Hardjanto (2010). Dengan demikian semakin disadari bahwa dalam suatu koperasi, SDM merupakan unsur yang paling penting, seperti yang diungkapkan oleh Hardyansyah (2002) bahwa manusia sebagai tenaga kerja dalam organisasi mempunyai peranan yang penting dalam mencapai tujuan dan memberikan pelayanan yang baik bagi organisasi dan masyarakat. Kinerja adalah hal yang mempengaruhi seberapa banyak mereka memberi kontribusi kepada koperasi. Perbaikan kinerja individu maupun kelompok menjadi perhatian dalam meningkatkan kinerja organisasi (Malthis dan Jackson, 2001). Beberapa faktor yang mempengaruhi kinerja individu, yaitu peraturan perusahaan, rekan kerja, pengawasan, kemampuan memotivasi dan pelatihan (Aamodt, 2010). Gomes (2003:171) mendefinisikan motivasi sebagai perilaku yang ditujukan pada sasaran. Dhermawan dkk. (2012) menunjukkan bahwa motivasi berpengaruh tidak signifikan terhadap kinerja karyawan. Kepuasan kerja adalah keadaan emosional 
karyawan di mana terjadi ataupun tidak terjadi titik temu antara nilai balas jasa karyawan dari perusahaan atau organisasi dengan tingkat balas jasa yang memang diinginkan oleh karyawan yang bersangkutan (Martoyo, 2007:156). Menurut Mudiartha (2001:257) sebabsebab ketidakpuasan beraneka ragam seperti hasil yang diterima rendah atau dirasakan kurang cukup memadai, kondisi kerja yang kurang memuaskan, hubungan yang tidak serasi baik dengan rekan kerja maupun dengan atasan, dan pekerjaan yang kurang sesuai dan lain - lain.

Berdasarkan uraian diatas, dengan melihat permasalahan dan kendala yang sudah dilihat di dalam bekerja, yang tidak mencapai output kinerja maksimal sesuai ketentuan yang ditetapkan oleh koperasi untuk mencapai salah satu predikat yang ditentukan oleh instansi pemerintahan. Maka dengan demikian akan menjadi sangat penting dan dipandang perlu untuk melakukan sebuah penelitian, dalam hal ini bagaimanakah meningkatkan atau mensosialisasikan koperasi agar partisipasi anggota berpengaruh terhadap kinerja koperasi melalui sosialisasi dan kepuasan kerja yang diterapkan oleh manajemen, untuk mengetahui

pengaruh antara anggota koperasi ,kepuasan kerja dan kinerja. Tujuan penelitian dirumuskan sebagai berikut :

1. Menganalisis pengaruh partisipasi anggota terhadap kinerja karyawan.

2. Menganalisis pelayanan SDM anggota terhadap pengurus

3. Menganalisis pengaruh kepuasan kerja terhadap kinerja karyawan.

\section{Metode Penelitian \\ Jenis metode data}

Studi ini memakai penelitian metode penelitian kuantitatif melalui pendekatan survei. Melalui metode ini gejala yang hendak dianalisis akan diteliti, di observasi dengan kuantitas

atau frekuensi tertentu yang dapat diukur dalam konteks inilah pendekatan survei dibutuhkan agar gejala social dan kinerja pengurus koperasi dapat diamati secara benar dan tepat. Hasil pengamatan itulah yang akan diolah dan dianalisis dengan tetap mematuhi objektivitas data sebagai suatu kebenaran ilmiah yang tetap berdiri sendiri.

\section{Sumber Data}

Data yang terkumpul adalah hasil survey wawancara langsung terhadap wakil ketua koperasi MMS warung sampah dengan hasil dari 3 tahun berdirinya koperasi tersebut telah mempunyai nasabah sebanyak 100 orang, termasuk 50 internal. Metode yang dilakukan dalam penelitian ini adalah metode pendekatan survey dengan membuat wawancara langsung terhadap wakil ketua koperasi dan 10 orang nasabah atau anggota koperasi.

Hasil dari wawancara tersebut ada beberapa tanggapan mengenai koperasi MMS tersebut :

1. Beberapa aktif untuk ber partisipasi dikoperasi MMS seperti penyuluhan mengontrol setiap rumah pedagang khusus didesa linggar untuk sandar lingkungan terawat dan sampah plastik nya juga bisa di daur ulang menjadi uang.

2. Pengurus belum bekerja optimal karena masyarakatnya juga belum semuanya sadar akan berpartisipasi terhadap MMS dari 100\% terdapat $75 \%$ masyarakat ikut berperan aktif dan sisanya bekerja sebagai buruh pabrik (karena disetiap pabrik sebagian mempunyai koperasi sendiri)

3. Pengurus berusaha mengurus koperasi tersebut sudah beberapa kali edukasi untuk mengajak masyarakat setempat

4. Menurut masyarakat luar yang mengikuti koperasi MMS, koperasi MMS sudah memenuhi standar kerja yang bagus dan optimal, karena didaerah linggar tersebut koperasi sampah mms hanya ada satu satunya dilinggar 
5. Koperasi MMS sudah masuk koperasi kriteria yang bagus dan belum ada permasalahan dan keluhan dari masyarakat

6. Koperasi MMS sangat mudah meminjamkan pinjaman dan membayarnya tanpa bunga yang besar dan tidak memberatkan kepada masyarakat dengan menghasilkan (mengumpulkan hasil sampah).

\section{Hasil dan pembahasan}

\section{Sumber Daya Manusia (SDM)}

Merupakan aspek penting dalam sebuah perusahaan dan Organisasi. Dan juga SDM merupakan kunci yang menentukan perkembangan perusahaan, pada hakikatnya SDM dipekerjakan sebagai penggerak, pemikir, dan perencana untuk mencapai tujuan yang diharapkan oleh perusahaan atau organisasi.

\section{Partisipasi anggota}

Partisipasi Anggota dalam koperasi merupakan mengikut serta kan anggota koperasi itu dalam kegiatan dalam organisasi dan pencapaian tujuan bersama. Thoby mutis dalam Edilius (1992:93) "partisipasi anggota merupakan unsur utama dalam memacu kegiatan dan untuk mempertahankan ikatan pemersatu didalam koperasi "secara harfiah partisipasi diambil dari bahasa asing participation, yang artinya mengikut serta kan pihak lain dalam mencapai tujuan.

Partisipasi diartikan Ropke (2003:52) "suatu peroses di mana sekelompok orang (anggota) menentukan dan mengimplementasikan ide-ide atau gagasan koperasi”

Bentuk partisipasi anggota :

Partisipasi anggota sebagai pemilik :

1. Partisipasi dalam pengambilan keputusan (PPK)

2. Partisipasi dalam pengawasan jalan kegiatan koperasi (PPP)
3. Partisipasi dalam kontribusi modal (PMK), baik melalui simpanan yang menentukan kepemilikan (Simpanan Pokok dan Simpanan Wajib) maupun simpanan yang tidak menunjukkan kepemilikan (Simpanan Sukarela,atau Tabkop, atau Sijakop)

4. Partisipasi dalam menanggung risiko, baik risiko pelayanan kepada anggota maupun risiko bisnis dengan non - anggota (PMR).

a. Partisipasi anggota sebagai anggota

1. Partisipasi dalam membeli barang atau jasa kebutuhan konsumen (dalam koperasi konsumen)

2. Partisipasi dalam memanfaatkan jasa simpanan dan pinjaman (dalam koperasi simpan - pinjam)

3. Partisipasi alam pembelian bahan baku dan input lainnya untuk kebutuhan produksi anggota (dalam koperasi produsen atau koperasi pengadaan)

4. Partisipasi dalam menjual hasil produksi atau output produksi (dalam koperasi produsen atau koperasi pemasaran)

5. Partisipasi dalam memanfaatkan pelayanan jasa lainnya misalnya: jasa asuransi, penjaminan hari tua, dan jasa jasa lainnya.

Hubungan partisipasi dengan studi penelitian ini adalah:

Menganalisis pengaruh partisipasi anggota terhadap kinerja karyawan: dalam ber partisipasinya anggota sangat berpengaruh untuk kinerja karyawan, tidak hanya menetukan hasil yang dimiliki anggota, tetapi untuk saling melengkapi kebutuhan satu sama lain, dan dengan partisipasi anggota pun akan 
meningkatkan perkembangan koperasi tersebut.

Di linggar sendiri dari hasil penelitian bahwa 100 orang termasuk 50 internal, dari persentase $100 \%$ terdapat $75 \%$ masyarakat ikut berperan aktif mengurus koperasi MMS tersebut:

\section{Partisipasi anggota}

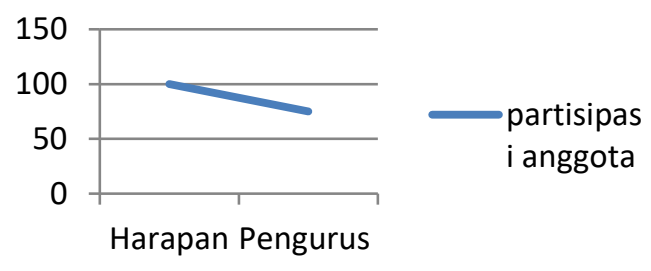

1. Menganalisis pelayanan SDM anggota terhadap pengurus: dalam koperasi MMS anggota harus berperan aktif dalam melakukan kegiatannya, tidak hanya mengumpulkan sampah, koperasi ini sendiri memudahkan memberi pinjaman dengan tingkat bunga yang rendah yang sudah ditentukan UKM untuk angka 7\% per tahun,bunga yang sangat relatif terjangkau, suku bunga tersebut juga sama dengan bunga kredit usaha rakyat atau yang biasa dikenal KUR. Tetapi di koperasi ini sendiri bisa membayarnya dengan kita mengumpulkan sampah rutinnan dan bisa menjadikan Uang yang didapatkan anggota untuk tidak mempersulit pengurus saat pembayar jatuh tempo pada anggota, sebagai contoh:

Tn. aep meminjam ke koperasi sebesar rp. 200.000 dengan bunga $7 \%$, Rp. $200.000 \times 7 \%=\ldots$

jika Tn aep tidak membayarnya dengan kembali uang tn. Aep bisa menukar nya dengan sampah yang bisa di daur ulang, tidak hanya sampah buku bekas yang masih layak pakai juga bisa, sampai hasil pengumpulan nya memenuhi pinjamannya dan bunga pun tertutup.

2. Menganalisis pengaruh kepuasan kerja terhadap kinerja karyawan. Dengan masyarakat terjun ke koperasi MMS tersebut maka koperasi MMS akan lebih maju, apalagi sejauh ini koperasi MMS belum terdengar per masalahannya, hanya saja anggota dari koperasi MMS sangan minim dikampung linggar tersebut, pengaruh kepuasan kinerja karyawan itu sendiri faktor dari pengumpulan hasil yang di kerjakan, koperasi MMS ini sangat memuaskan anggota dengan karyawan membantu untuk memfasilitasi penampungan nya barang bekas yang bisa di daur ulang atau yang masih bisa dipakai, lalu mempunyai perpustakaan sederhana tersendiri dengan mengumpulkan buku, majalah yang masih layak dan masih bisa dibaca oleh pembaca, dan kinerja karyawan harus memeriksa setiap pemberi sampah yang harus disortir agar bisa memilih mana yang layak pakai, dari kampung linggar itu sendiri, koperasi satu - satunya koperasi sampah yang mengelola barang bekas yang layak pakai atau pendauran ulang, maka sangat efektif bagi koperasi.

\section{Kesimpulan dan Saran}

Kesimpulan studi ini menggunakan kuantitatif di mana menguji nilai terhadap pengaruh SDM terhadap partisipasi anggota, dengan adanya koperasi sampah kita bisa lebih merawat lingkungan dan memanfaatkan barang yang masih layak pakai atau mendaur ulang nya dengan menghasilkan pendapatan, dan koperasi sampah ini sangat memudahkan anggotanya untuk simpan - pinjam dengan ketentuan yang sudah disepakati sebelumnya. 
Atas pengaruhnya pengurus di dalam koperasi ini dilihat dari jumlah anggota yang lebih dari 100 orang dan dari hasil wawancara maka disimpulkan bahwa pengaruh pengurus dan kinerjanya cukup berpengaruh terhadap kemajuan koperasi MMS ini.

\section{SARAN}

1. Mewujudkan koperasi sebagai central Ekonomi dengan menyediakan bahan-bahan kebutuhan masyarakat melalui pembangunan usaha yang skalanya lebih besar.

2. Melakukan sosialisassi lebih luas terhadap koperasi.

3. Memberikan pengaruh baik terhadap masyarakat terhasap koperasi MMS ini.

\section{Daftar Pustaka}

1. Astawa, I. G. P. B., Julianto, I. P., \& Dewi, L. G. K. (2020). Penilaian Kinerja Koperasi Unit Desa (KUD) Penebel Tabanan dengan Pendekatan Balanced Scorecard. MONEX, 9(1), 18-29. Faedlulloh, D. (2015). Modal Sosial dalam Gerakan Koperasi. IPJA-the Indonesian Journal of Public Administration, 2(1). Ikhsan, A. E. (2013). Analisis Kinerja Koperasi. Pekbis Jurnal, 5(1), 41-50.
2. Yustien, Reni Pengaruh Penerapan Sistem Pengendalian Manajemen Pada Pendapatan Dan Pusat Biaya Terhadap Kinerja Manajerial Rumah Sakit Umum Tipe B di Provinsi Jawa Barat, Dosen Jurusan Akuntansi Fakultas Ekonomi Universitas Jambi 46.

https://pekbis.ejournal.unri.ac.id/index .php/JPEB/article/view/428/422

3. https://scholar.google.com/scholar? $\mathrm{hl}=\mathrm{id} \&$ as_sdt $=0 \% 2 \mathrm{C} 5 \& \mathrm{q}=$ pengaru $\mathrm{h}+\mathrm{sdm}+$ terhadap+kinerja+koperasi \&oq=pengaruh+sdm+terhadap+kin erja+koper

4. https://journal.uny.ac.id/index.php/ economia/article/view/8281

5. http://koperasi.bandungkab.go.id/in dex.php/c_home/daftar_koperasi_a ktif.jsp

6. Modul perkoperasian Institut Koperasi indonesia 2019

7. https://www.akseleran.co.id/blog/pi njamankoperasi/\#: :text=Kementerian\%20 Koperasi\%20dan\%20UKM\%20me netapkan,biasa\%20dikenal\%20den gan\%20nama\%20KUR. 